\title{
African Easterly Wave Dynamics in a Mesoscale Numerical Model: The Upscale Role of Convection
}

\author{
GARETH J. BERRY \\ Monash Weather and Climate, Monash University, Clayton, Victoria, Australia \\ CHRIS D. THORNCROFT \\ University at Albany, State University of New York, Albany, New York
}

(Manuscript received 13 April 2011, in final form 2 October 2011)

\begin{abstract}
To examine the dynamical role of convection in African easterly wave (AEW) life cycles the Weather Research and Forecasting (WRF) model is used to simulate the evolution of a single AEW from September 2004. The model simulations are validated against corresponding numerical weather prediction analyses and the mean fields closely resemble composite structures from previous studies. A potential vorticity (PV) thinking approach is used to highlight the interactions between dynamics and convection.

Organized deep convection embedded within the AEW has a large contribution to the synoptic-scale mean $\mathrm{PV}$ and energetics of the AEW. The PV tendency is maximized in the lower troposphere, consistent with the vertical gradient in diabatic heating rates in the areas of convection. By examining terms in the Lorenz energy cycle, it is shown that diabatic heating associated with convection is as important as adiabatic energy conversion in producing eddy available potential energy of the synoptic AEW, implying that AEWs are best described as hybrid adiabatic and diabatic structures. The net effect of convection is succinctly described using a simulation whereby the parameterizations associated with convection are switched off at the midpoint of the model run. This perturbation experiment shows that, although the AEW continues to propagate westward with a similar phase speed, the net PV value continually weakens with time. This result proves that convection is vital for the maintenance of the AEW as it propagates across West Africa and suggests that without active convection the synoptic AEW cannot persist for an extended length of time.
\end{abstract}

\section{Introduction}

Much of the current understanding of African easterly wave (AEW) dynamics is driven by synoptic studies, especially those of Carlson (1969a,b), Burpee $(1972,1974)$, and Reed et al. (1977). These works have suggested that dry dynamics predominantly govern the growth and maintenance of synoptic AEWs, whereby AEW growth can be attributed to dynamic instability of the midtropospheric (peaked near $650 \mathrm{hPa}$ ) African easterly jet (AEJ). These studies have demonstrated that AEWs grow by baroclinically and barotropically extracting energy from this ubiquitous component of the summertime West African monsoon system. These conclusions were supported by energy calculations based on field data

Corresponding author address: Gareth J. Berry, Monash Weather and Climate, Monash University, Clayton, Victoria, 3800, Australia. E-mail: gareth.berry@monash.edu
(Norquist et al. 1977) and idealized modeling studies (e.g., Thorncroft and Hoskins 1994). While a prominent feature in all AEW observation work and often highlighted as a potential factor, there is no detailed understanding of the dynamical role of convection on synoptic scales. Norquist et al. (1977) suggested that "over West Africa the condensation heating becomes a dominant factor for their [AEW] growth and sustenance", but primarily owing to the lack of appropriate observations this has only recently begun to be considered [e.g., in a modeling study by Hsieh and Cook (2007)].

From a dynamical perspective, it is well known that mesoscale convection is capable of generating atmospheric circulations and temperature anomalies that can influence regions larger than their precipitation footprint (see, e.g., Houze 2004). These concepts, promoted within a potential vorticity (PV) framework, have been previously applied in the context of AEWs by Berry and Thorncroft (2005, hereafter BT05). Based on the synoptic analysis of a single 
AEW case, these authors suggested that the aggregate circulation and temperature anomalies associated with MCSs embedded in the AEW could grow upscale and impact the synoptic-scale growth of the AEW. The need for an energetic source other than instability of the AEJ was suggested by Hsieh and Cook (2005), who suggested that the PV gradients associated with their simulated AEJ were insufficient to support growing AEWs and also by Hall et al. (2006), who demonstrated that the AEJ is actually stable to small amplitude perturbations in the presence of realistic friction. BT05 presented a conceptual model of a mature AEW, which proposed that a dynamical feedback existed in a similar fashion to the conceptual "diabatic Rossby wave" discussed by Parker and Thorpe (1995) where diabatically generated PV anomalies supplement, or act as a surrogate for, a synopticscale Rossby wave in a baroclinic environment. A similar conclusion was reached from a climatological perspective by Hsieh and Cook $(2007,2008)$, who suggested that convection is an important energy source for AEWs and shear instabilities of the AEJ sustain AEWs in their decaying stages rather than initiate the disturbances.

The aim of this paper is to examine the four-dimensional evolution of an AEW with the aim of detailing the scale interactions between the synoptic AEW and the embedded convection. Using the conceptual model put forward by BT05 as a basis, here the upscale role of convection on the synoptic dynamics of an AEW is explored. The overall approach taken is relatively simple: a full-physics mesoscale numerical model is used to simulate an AEW case to generate self-consistent, high-resolution datasets with which a thorough process study is conducted. Simulations are used owing to the need for physically consistent and contemporaneous diabatic heating fields at high resolution, which are not directly available from observations. Using a model rather than a numerical reanalysis allows us to conduct perturbation experiments to test specific results and to determine the sensitivity to the way in which convection is represented in the model. In particular, the model is run without convection so as to break down the physics of AEWs, which is not achievable with observations or reanalysis. Conversely, a major advantage of a reanalysis dataset is the larger number of cases, so the overarching results will be compared against a composite AEW generated from a 20 -yr reanalysis product to ensure that the results are robust and more widely applicable.

The paper is organized as follows: section 2 describes the methodology including numerical model setup, characteristics, and experimental design along with a description of the analysis techniques. Section 3 presents the main results from the numerical simulations, and section 4 compares the simulation results with a composite AEW structure from a numerical reanalysis product. The discussion and conclusions are presented in section 5 .

\section{Methodology}

All simulations presented in this article are conducted using the National Center for Atmospheric Research Weather Research and Forecasting (WRF) model version 3 (Skamarock et al. 2008). A single long-lived AEW from September 2004 is simulated as it propagates from central Africa to the West African coast. The case selected was first detected by the objective AEW diagnostics described by Berry et al. (2007) for 0000 UTC 3 September 2004 as a relatively small-scale feature near $30^{\circ} \mathrm{E}$ over Sudan. Over the following six days this AEW traverses the African continent and leaves the West African coast at 1200 UTC 9 September as a well-defined synoptic-scale system. The synoptic evolution is similar to the case documented by BT05 and was selected for analysis by being the most "average" AEW of the 2004 season in that its mean intensity (measured by the $700-\mathrm{hPa}$ curvature vorticity value) and its propagation speed were the closest to the 2004 season mean values (see Berry et al. 2007).

The WRF model simulations are initialized at 1200 UTC 3 September 2004 and run for six days $(144 \mathrm{~h})$, when the real AEW case reaches the West African coast (approximately $15^{\circ} \mathrm{W}$ ). The simulations are run with a $50-\mathrm{km}$ horizontal resolution on a model grid centered on tropical North Africa that has 300 points in the zonal direction and 135 in the meridional direction. The model data is output every $3 \mathrm{~h}$, although to allow for model spinup the first $24 \mathrm{~h}$ of the simulations are not examined. A map showing the extent of the model domain is shown in Fig. 1. This large domain was chosen to minimize any impact of input from the lateral boundaries on the system of interest. There are 28 vertical levels, which are linear in the WRF model's native mass-based terrain following vertical coordinate giving in highest vertical resolution in the lower troposphere. The WRF simulations are initialized using the National Centers for Environmental prediction (NCEP) Final (FNL) analysis at $1^{\circ}$ resolution. During the simulations no assimilation or nudging occurs on the model domain (the WRF model is free running), but the lateral boundary conditions and sea surface temperatures are updated every $6 \mathrm{~h}$ from the FNL analyses.

Because the WRF model has numerous physical parameterizations options, which are designed with different philosophies and specific applications in mind, preliminary testing was conducted to select the optimum combination of physical parameterizations for the simulations. As might be anticipated, initial testing revealed significant sensitivity to the representation of cloud 


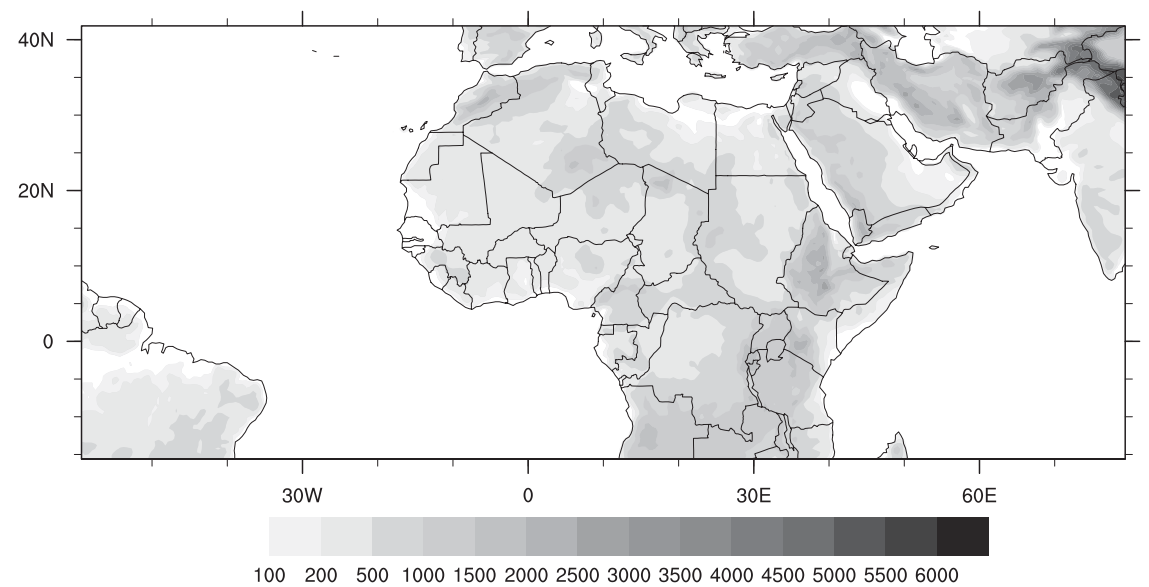

FIG. 1. Map showing the model domain and terrain height $(\mathrm{m})$ used in the WRF simulations.

processes, thus model configurations using different parameterizations of microphysical $(\mathrm{Mp})$ and cumulus $(\mathrm{Cu})$ processes were compared. This comparison consisted of repeating a simulation of the first 10 days of September 2004 with a lower-resolution $(250 \mathrm{~km}, 2$-min time step) version of the domain shown in Fig. 1. The wind field at $925,850,700,500$, and $200 \mathrm{hPa}$ were subjectively compared with the FNL analyses and the rainfall was compared with the Tropical Rainfall Measuring Mission (TRMM) 3B42 product (see Huffman et al. 2007) using Hovmöller space-time diagrams (not shown). Although all 32 configurations tested produced westward propagating synoptic-scale weather systems, the following parameterizations were selected for what is henceforth termed the "main simulation":

- new Grell 3D cumulus scheme

- Thompson graupel microphysics scheme

- Rapid Radiative Transfer Model longwave radiation scheme

- Dudhia shortwave radiation scheme

- Mellor-Yamada-Janjic (Eta) TKE vertical mixing scheme

- Monin-Obukhov (Janjic Eta) surface layer scheme

- thermal diffusion land surface scheme.

To provide a measure of uncertainty associated with the model physics and to determine how robust the overall conclusions are, the entire simulation is rerun four times at $50-\mathrm{km}$ resolution using two alternative $\mathrm{Cu}$ or $\mathrm{Mp}$ parameterizations. In each rerun experiment, detailed in Table 1, one of the $\mathrm{Cu}$ or $\mathrm{Mp}$ parameterizations options are the same as in the main simulation. This set of five experiments is viewed as an ensemble with the different simulations viewed as members. In the analysis, the ensemble mean of quantities will be shown and the spread of the individual simulations will provide a measure of uncertainty associated with the choice of model physics. The ensemble mean, rather than a single simulation, is used because all the parameterizations have some physical basis, and without a validation dataset it is not possible to determine which is the most representative of convection in this region. Because this work is concerned with the role of moist convection in AEW dynamics, this is examined by conducting a further simulation whereby moist convection is instantaneously removed part way through. This perturbation experiment (henceforth called the "dry run") consists of conducting the main simulation as described above for the first $72 \mathrm{~h}$ and then completing the remaining $72 \mathrm{~h}$ of integration with no $\mathrm{Cu}$ or $\mathrm{Mp}$ parameterizations. The length of the dry run is limited as moist convection plays a part in maintaining the basic state (Thorncroft and Blackburn 1999; Hsieh and Cook 2005) and a longer integration would create a basic state that is less realistic. The

TABLE 1. List of WRF simulations. More details of the specific parameterization schemes are provided by Skamarock et al. (2008).

\begin{tabular}{cllll}
\hline \hline Model run & Cumulus scheme & \multicolumn{1}{c}{ Microphysics scheme } & Text abbreviation \\
\hline 1 & Kain-Fritsch & Thompson graupel & Cu1 Mp8 \\
2 & Betts-Miller-Janjic & Thompson graupel & Cu2 Mp8 \\
3 & New Grell & Ferrier & Cu5 Mp5 & Cu5 Mp7 \\
4 & New Grell & Goddard Cumulus Ensemble & Cu5 Mp8 & Main simulation \\
5 & New Grell & Thompson graupel & Dry & \\
6 & None & None & & \\
\hline
\end{tabular}


results from the dry run will be contrasted with the main simulation.

The data in each simulation are examined using the objective AEW trough diagnostics developed by Berry et al. (2007) at $700 \mathrm{hPa}$, with the center of the AEW being defined as the intersection of the objective trough axis and wind speed maxima in the latitude band $5^{\circ}-20^{\circ} \mathrm{N}$. Due to the nonglobal model domain, the objective diagnostics are computed using the total wind field rather than the nondivergent wind. In cases where multiple trough axes exist within the AEW the mean longitude of all axes is used in this definition, and in cases where the trough axis is ill defined the data is omitted from analysis. This procedure allows system-relative fields to be computed and the different simulations to be compared, as well as allowing an objective composite to be produced from the WRF simulations.

The composite fields from the WRF simulations are compared to a composite AEW generated from the interim European Centre for Medium-Range Weather Forecasts Reanalysis (ERA-Interim) dataset (hereafter ERAI). The data used have $1.5^{\circ}, 6$-h resolution on 29 isobaric levels. Using the Berry et al. (2007) diagnostics, AEWs are detected based on the 700-hPa wind field in the ERAI during the July-September period for 19892008. The 430 cases detected during this period between $10^{\circ} \mathrm{W}$ and $10^{\circ} \mathrm{E}$ are transposed to the same location using the objectively defined AEW center (the intersection of the AEW trough and wind speed maximum) to form a composite. As noted previously these reanalysis data do not provide diabatic heating estimates, so this is crudely estimated using the TRMM 3B42 rainfall product combined with idealized heating profiles from Schumacher et al. (2004). This provides an estimation of the vertical profile of heating based purely upon the surface rainfall rate. The TRMM data at $0.5^{\circ}$ and 3 -h resolution is available for 1998-2008. Although the record length of the TRMM data is less than that of the ERAI, all applicable cases are merged with the composite reanalysis data for illustrative calculations.

\section{Results}

\section{a. Overview of the WRF model simulations}

The overall quality of the WRF simulations is assessed by comparing the model output with the ERAI dataset valid for the same period and comparing broad characteristics. A Hovmöller space-time diagram of the meridional wind at $700 \mathrm{hPa}$, averaged between $5^{\circ}$ and $15^{\circ} \mathrm{N}$, is shown in Fig. 2 for each member of the WRF ensemble alongside the equivalent from the ERAI reanalysis. In each panel the location of the objectively derived AEW center, which is used in the compositing and system relative calculations, is overlain. Each WRF simulation is able to propagate and intensify the weak initial disturbance across the African continent in a manner closely resembling the ERAI. The length scale of the disturbance in each WRF simulation is similar to that seen in reality (approximately $3000 \mathrm{~km}$ ) and the propagation speed is practically identical (approximately $9.5 \mathrm{~m} \mathrm{~s}^{-1}$ ).

All members of the WRF ensemble produce the observed intensification of the AEW as it passes $10^{\circ} \mathrm{E}$. The amplitude of the meridional wind is larger than the reanalysis in all simulations, although this is anticipated because the WRF domain has 3 times the horizontal resolution of the ERAI. Note that in some WRF simulations there is a jump in the overlaid track near 0000 UTC 7 September; this is due to a strong pulse of convection that redefined the location of the AEW trough axis, as is observed in some real AEW cases (Berry et al. 2007). This serves as a reminder of the impact of convection in the tropics where synoptic amplitudes are often small. As expected from numerical forecasts, skill deteriorates with time and the WRF simulations give a poor forecast of the trailing AEW, with all members suggesting a much stronger system than seen in ERAI. This event occurs several days into the forecast integration in a region of few in situ observations, and the trailing event is not examined in this study - thus unlikely to significantly influence the overall results and conclusions.

Another assessment of the WRF model forecast performance and the member-to-member variability is given in Fig. 3, where some synoptic fields 6 days into the simulations are displayed alongside the ERAI valid at the same time (1200 UTC 8 September 2004). Significant differences do exist between ensemble members at this late stage of the forecast integration, but the structures produced are all recognizable as AEWs from synoptic experience and are broadly consistent with the ERAI. In each member, a synoptic-scale trough is collocated within a curved portion of the AEJ axis at $700 \mathrm{hPa}$. Similar to the case described by BT05, this is in concert with a wavelike perturbation to the zonally oriented PV strip on the equatorward flank of the AEJ. Embedded within this PV strip are intense subsynoptic-scale PV maxima associated with deep convection. There is variety in the number and shape of the individual PV maxima, but they all share a common (subsynoptic) scale and are focused near the center of the synoptic-scale AEW. The dynamical influence of the convectively generated PV maxima can be appreciated from the different objective trough locations in each simulation. Consistent with the observations of Berry et al. (2007), the rapid development of convectively generated PV maxima 


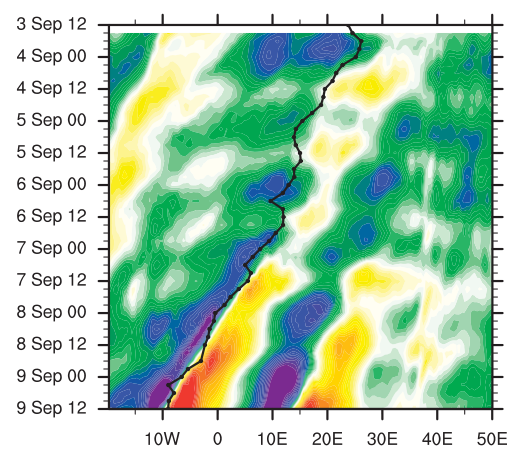

(a) $\mathrm{Cu} 1 \mathrm{Mp} 8$

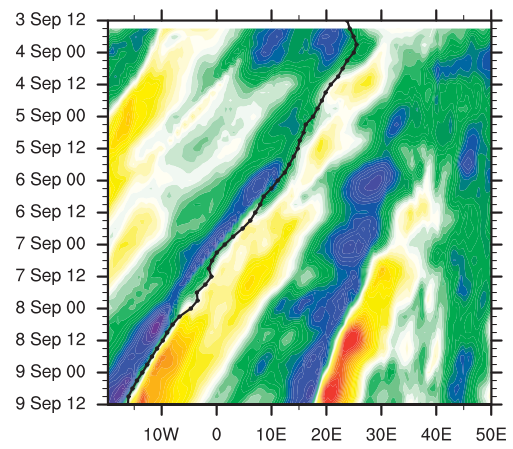

(d) Cu5 Mp7

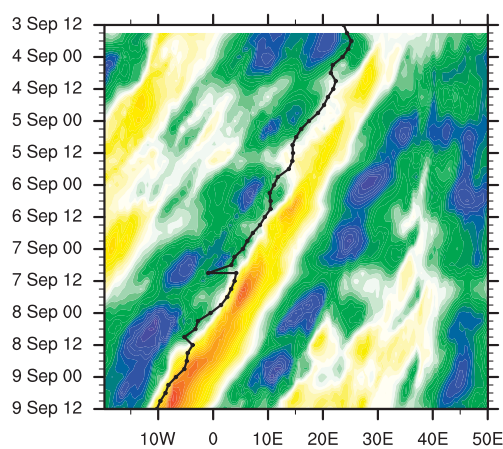

(b) Cu2 Mp8

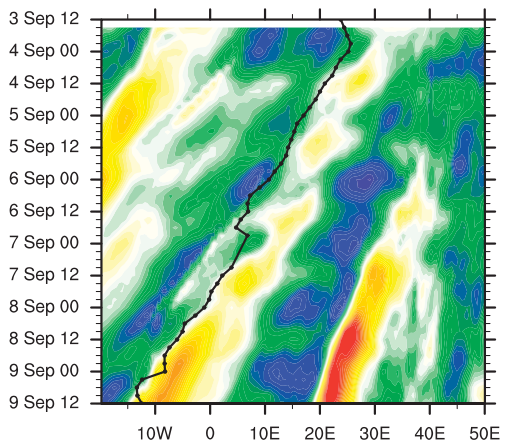

(e) Cu5 Mp8

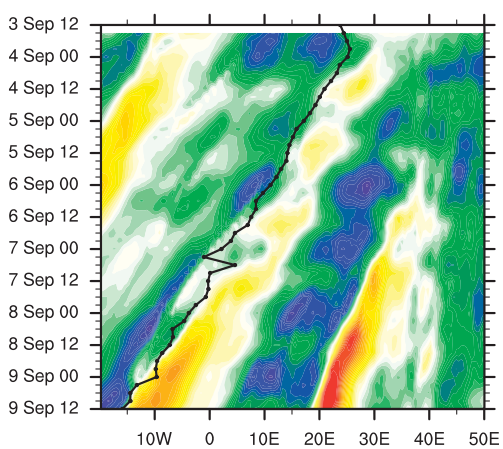

(c) $\mathrm{Cu} 5 \mathrm{Mp} 5$

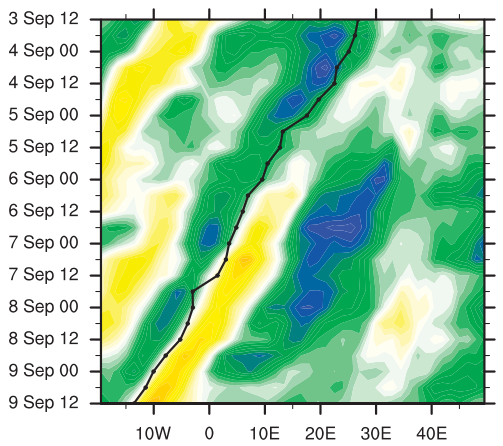

(f) ERA-Interim

\section{$\begin{array}{llllllllllllllllllllll}-10 & -9 & -8 & -7 & -6 & -5 & -4 & -3 & -2 & -1 & 0 & 1 & 2 & 3 & 4 & 5 & 6 & 7 & 8 & 9 & 10\end{array}$}

FIG. 2. Hovmöller space-time diagrams of 700 -hPa meridional wind, averaged over $5^{\circ}-15^{\circ} \mathrm{N}$, for (a)-(e) the five WRF simulations (see Table 1 for more details) and (f) the ERA-Interim. The location of the objectively defined AEW center (see text for definition) is indicated by the black dots and joined with a line for clarity.

rapidly shifts the alignment of the objective trough lines and in some instances is seen to retrogress or become indistinguishable for short periods (see Fig. 2).

For comparison with composite structures presented by previous work, maps of some ensemble mean synoptic fields are shown in Fig. 4. The fields are averaged across all five ensemble members for each 3-h output time when the simulated AEWs were in the region $10^{\circ} \mathrm{W}-10^{\circ} \mathrm{E}$. By definition, the objective AEW trough and the African easterly jet axes meet at the center of the composite. Like the synoptic snapshots shown in Fig. 3, the 700-hPa PV field is characterized by low values poleward of the AEJ axis and a wavelike perturbation equatorward. Within the high PV regional single subsynoptic-scale maximum exists near the $700-\mathrm{hPa}$ objective trough axis. This single maximum is the average of multiple subsynoptic-scale PV anomalies in the different WRF simulations (cf. Fig. 3). The mean potential temperature at $900 \mathrm{hPa}$ (Fig. 4a) also exhibits a well-defined synoptic-scale wavelike structure on the low-level baroclinic zone. The warm part of this potential temperature wave lies approximately $500 \mathrm{~km}$ ahead and north of the AEW center and the cold part lies approximately the same distance behind the trough axis. The configuration of these warm and cold anomalies at low levels and the midlevel PV structure is consistent with baroclinic growth, as described by BT05.

The mean flow at $700 \mathrm{hPa}$ (Fig. 4b) consists of an open wave, with the zonal flow dominating, whereas at $925 \mathrm{hPa}$ there is a significant meridional component of the flow, with southwesterly winds occurring in the region equatorward of the AEJ axis. Maximum low-level vorticity occurs poleward of the AEJ axis and ahead of the 700-hPa trough axis, close to the warm section of the wave in the low-level potential temperature. The rainfall field indicates that maximum precipitation is located in the $400-\mathrm{km}$ region immediately ahead of the AEW trough axis, where there is a significant northerly component of the wind at $700 \mathrm{hPa}$. Note that the maximum rainfall and maximum midlevel PV are displaced from 

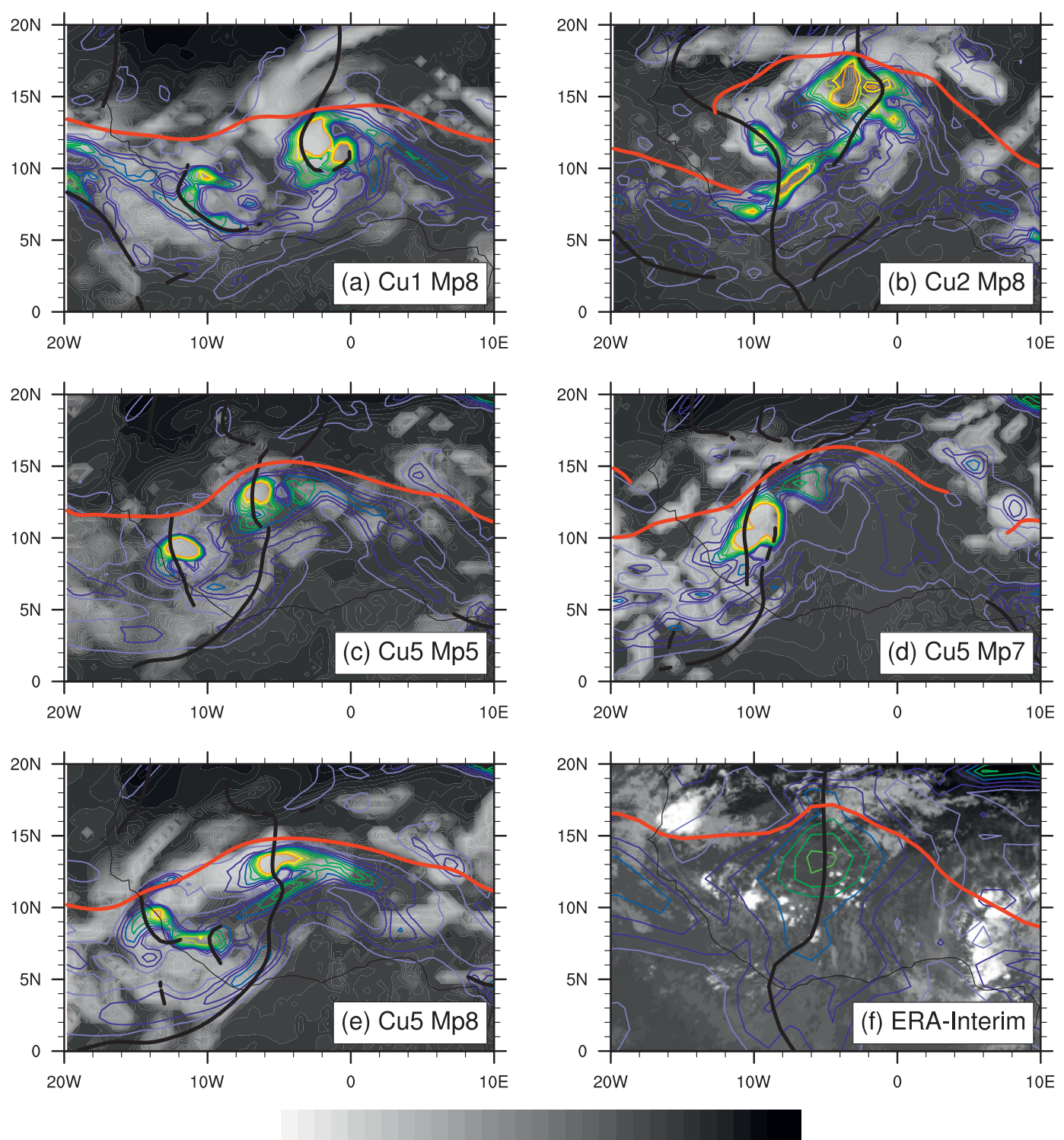

70100130160190220250280310340

FIG. 3. (a)-(e) Synoptic maps of the WRF simulations after 6.5 days of integration along with (f) the equivalent time from the ERA-Interim. The maps show 700-hPa PV (colored contours drawn every 0.1 PVU for greater than 0.1 PVU), with objective AEW and AEJ axes at $700 \mathrm{hPa}$ (solid black and red lines, respectively). In the WRF simulations this is overlaid on model outgoing longwave radiation (legend at base of figure; $\mathrm{W} \mathrm{m}^{-2}$ ) and in the ERAInterim the data are overlaid on infrared satellite imagery.

one another: the possible physical reasons for this are discussed later. Overall, the analysis presented here shows that the WRF simulations produce a mean AEW structure that closely matches both the observed case in the ERAI and composite AEWs in this region (see, e.g., Kiladis et al. 2006), giving increased confidence that the analysis below is valid. A more detailed comparison of these simulations to a composite derived from a large number of cases in the ERAI dataset is presented in section 4.

\section{b. Potential vorticity analysis}

The mean PV averaged between 1 and $5 \mathrm{~km}$ in a $10^{\circ} \times$ $10^{\circ}$ region following the objective AEW center is displayed by a time series in Fig. 5. In each simulation volume averaged PV tends to increase through the integration so that by the end of the simulation the ensemble mean boxaveraged PV has approximately doubled its original value. Superimposed on this trend is a diurnal cycle in which the PV values vary by approximately $25 \%$ between local 

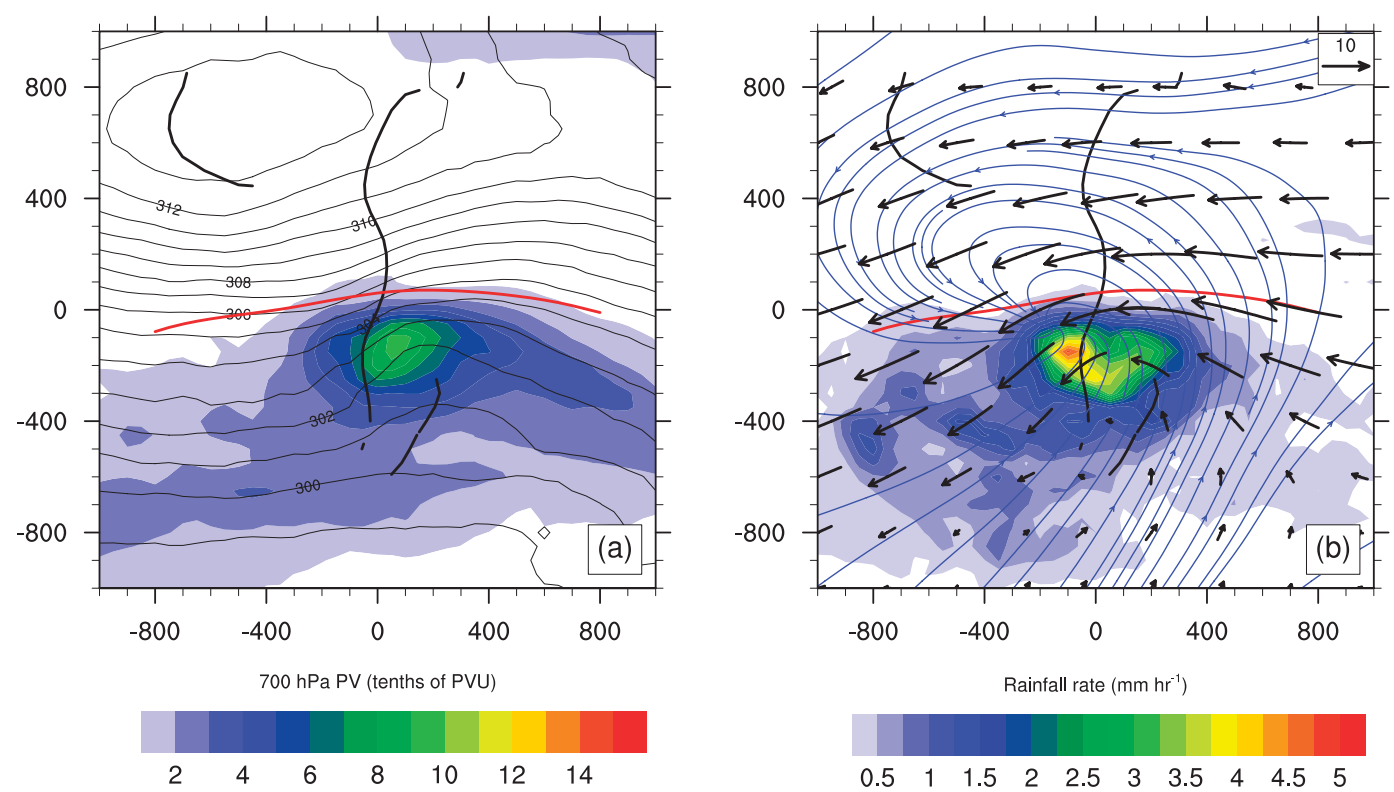

FIG. 4. Ensemble mean synoptic maps from the five WRF simulations, computed using all periods when the objectively identified AEW centers were between $10^{\circ} \mathrm{E}$ and $10^{\circ} \mathrm{W}$. (a) 700 -hPa potential vorticity (colored lines, 0.1 PVU), 925-hPa potential temperature (thin black lines, K), 700-hPa objective trough axes (thick black line), and 700$\mathrm{hPa}$ objective jet axes (thick red line). (b) Mean precipitation rate $\left(\mathrm{mm} \mathrm{h}^{-1}\right.$, shaded according to legend), streamlines at $925 \mathrm{hPa}$ (blue streamlines), and wind vectors at $700 \mathrm{hPa}$. The same objective trough and jet axes as in (a) are overlaid. Data are shown in system-relative coordinates with plot axes labeled in $\mathrm{km}$ from the objective AEJ center.

dawn and dusk (approximately 0600 and 1800 UTC). The PV values are weakest near 1800 UTC because during the day solar insolation drives the boundary layer temperature profile toward neutral stability and lower PV values. Conversely, the PV values are largest near 0600 UTC because of the nighttime cooling of the surface and the establishment of a stable nocturnal boundary layer (e.g. Parker et al. 2005a). The spread of the time series illustrates the strong influence of (parameterized) convection upon the PV budget of the intensifying AEW (cf. Hsieh and Cook 2008); although the simulations all behave in a similar fashion, the most intense simulation is almost double the strength of the least intense. Although this does not affect the overall results from a conceptual perspective, it illustrates that for operational purposes (e.g., tropical cyclone genesis forecasting), the model physics and their specific characteristics can be extremely important.

Because of the vastly different low-level environments and convective activity on either side of the AEJ core (see, e.g., Thorncroft and Blackburn 1999; Parker et al. 2005b), it is expected that the vertical profiles of PV and diabatic heating differ significantly in different regions of the AEW. Using the same system-relative regions as Fig. 5 , the ensemble mean vertical profiles of the diabatic terms are shown for each type of physical parameterization in Fig. 6, all averaged for the 5-day period from $24 \mathrm{~h}$ after model initialization until the end of the simulation. The diabatic PV tendency shown on the right-hand side of this figure is a product of the vertical derivative of diabatic heating and the environmental mean PV (not shown). The data are shown as ensemble mean values in two boxes, $5^{\circ}$ latitude $\times 10^{\circ}$ longitude, located north and south of the objective AEW center (i.e., the domain shown in Fig. 4 split into northerly and southerly sections).

In the poleward box (Fig. 6a), the largest diabatic tendency is heating from the vertical diffusion (often referred to as the boundary layer) scheme at the lowest model levels. This mean tendency drops to zero by $4 \mathrm{~km}$, close to the observed top of the Saharan boundary layer (see Parker et al. 2005b). In this region, the ensemble mean heating from cumulus parameterization is relatively weak and the radiation scheme produces diabatic cooling throughout the depth of the troposphere. Consequently, the net diabatic heating rate is very small (less than $2 \mathrm{~K} \mathrm{day}^{-1}$ ) with relatively small vertical gradients. In this poleward region, the lower troposphere mean PV is relatively small due to the temperature stratification and, thus, the net PV tendency (Fig. 6b) is also small.

In contrast, the diabatic heating profiles and PV tendencies are quite different equatorward of the AEW center (Figs. 6c,d). In particular, the cumulus parameterization scheme, which is positive through most of the 


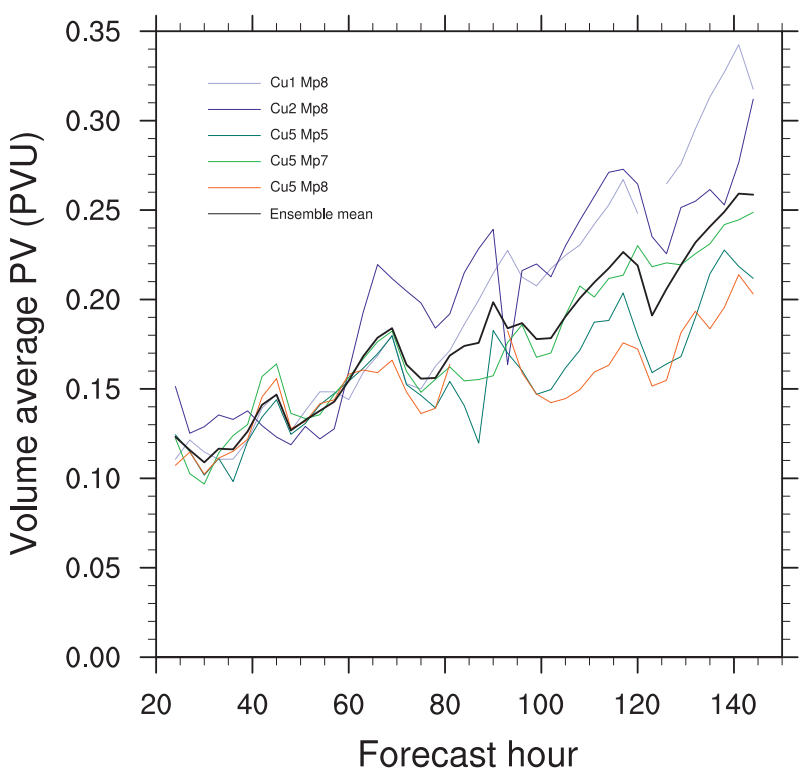

FIG. 5. Time series of potential vorticity (PVU) in each WRF simulation, volume averaged from 1 to $5 \mathrm{~km}$ altitude, within $10^{\circ}$ latitude/longitude of the objectively defined AEW center at each 3-h output time. The different simulations are denoted by the different colors; ensemble mean shown by the black line.

troposphere, dominates the total diabatic heating. The largest vertical gradient of total diabatic heating occurs between 2 and $4 \mathrm{~km}$, which leads to the greatest diabatic PV tendency (Fig. 6d) near $3 \mathrm{~km}(700 \mathrm{hPa})$, approximately the altitude of the largest observed AEW amplitudes and the peak of the AEJ (see Hsieh and Cook 2005). In both regions, the heating from the microphysical parameterization is close to zero, owing to cancellation and the lack of condensation from large-scale vertical motion compared to that of deep convection.

To examine the amount of uncertainty associated with using model parameterizations of diabatic processes, Fig. 7 shows the total diabatic heating rates and PV tendencies for each of the WRF ensemble members, again subdivided by regions north and south of the AEW center. Four of the five WRF simulations (the exception being $\mathrm{Cu} 2 \mathrm{Mp} 8$ ) show similar diabatic heating rates and PV tendencies; in the northern box both are close to zero throughout most of the troposphere and in the southern box the heating rates are close to $10 \mathrm{~K}_{\text {day }}{ }^{-1}$ above the 4-km level. A strong positive vertical gradient exists below this level, resulting in peak PV tendency between 2 and $4 \mathrm{~km}$. The net heating rates from these four simulations broadly resemble the combined deep convective and stratiform heating profiles proposed by Schumacher et al. (2004), based on the observations by Cifelli and Rutledge (1998). This heating profile is the combination of a stratiform and deep convective heating profile. The stratiform portion is characterized by net heating at upper levels (due to condensation in the anvil region) and cooling at low levels (due to evaporation below the freezing level, which is found near $5 \mathrm{~km}$ over tropical West Africa). The deep convective heating profile consists of a single strong heating maximum in the lower troposphere resulting from condensation in the strong vertical updraft.

The outlying WRF simulation, which utilizes the BettsMiller-Janjic (BMJ) cumulus parameterization, exhibits diabatic heating rates systematically different from the other simulations in both regions. The BMJ scheme produces strong heating near $5 \mathrm{~km}$ (approximately the freezing level), with cooling near 2 and $8 \mathrm{~km}$. The net result in both regions is diabatic generation of PV near $3 \mathrm{~km}$ and destruction near $7 \mathrm{~km}$. From an overall perspective, this simulation is very different from the other four and is inconsistent with observations and conceptual expectations. However, from the analysis of simulation shown previously (e.g., Figs. 2-4) this particular simulation does not stand out as being particularly different to the others thus far. Although one would expect there to be large dynamical consequences from the differences, it has been minimized to this point as AEWs are maximized at low levels (i.e., below $5 \mathrm{~km}$ ) where the diabatic heating rates and their vertical gradients are similar across all WRF simulations.

\section{c. Energetics}

As discussed previously, the ensemble mean synoptic structure (Fig. 4) has a configuration consistent with baroclinic growth, and the analysis of the diabatic PV tendencies have shown that the subgrid-scale convection generates $\mathrm{PV}$ at the same level as the observed synoptic PV maxima. However, the fundamental question as to which is dominant in controlling the synoptic dynamics of AEWs is so far unaddressed. If dry baroclinic growth dominates, AEWs could be described as Rossby waves, whereas if the diabatic generation of PV controls the dynamics they could be described as synoptic-scale coherent diabatic vortices. As discussed by Moore and Montgomery (2005), following the framework laid out by Parker and Thorpe (1995), these types of synoptic systems can be differentiated by comparing terms in the Lorenz energy cycle (Lorenz 1955). These authors determined whether the synoptic system is dominated by adiabatic or diabatic dynamics by considering the relative magnitudes of the following terms:

$$
\mathrm{GE}=\int_{p 1}^{p 2} \frac{\overline{\left[Q^{\prime} T^{\prime}\right]}}{c_{p} \bar{\sigma}} d p
$$



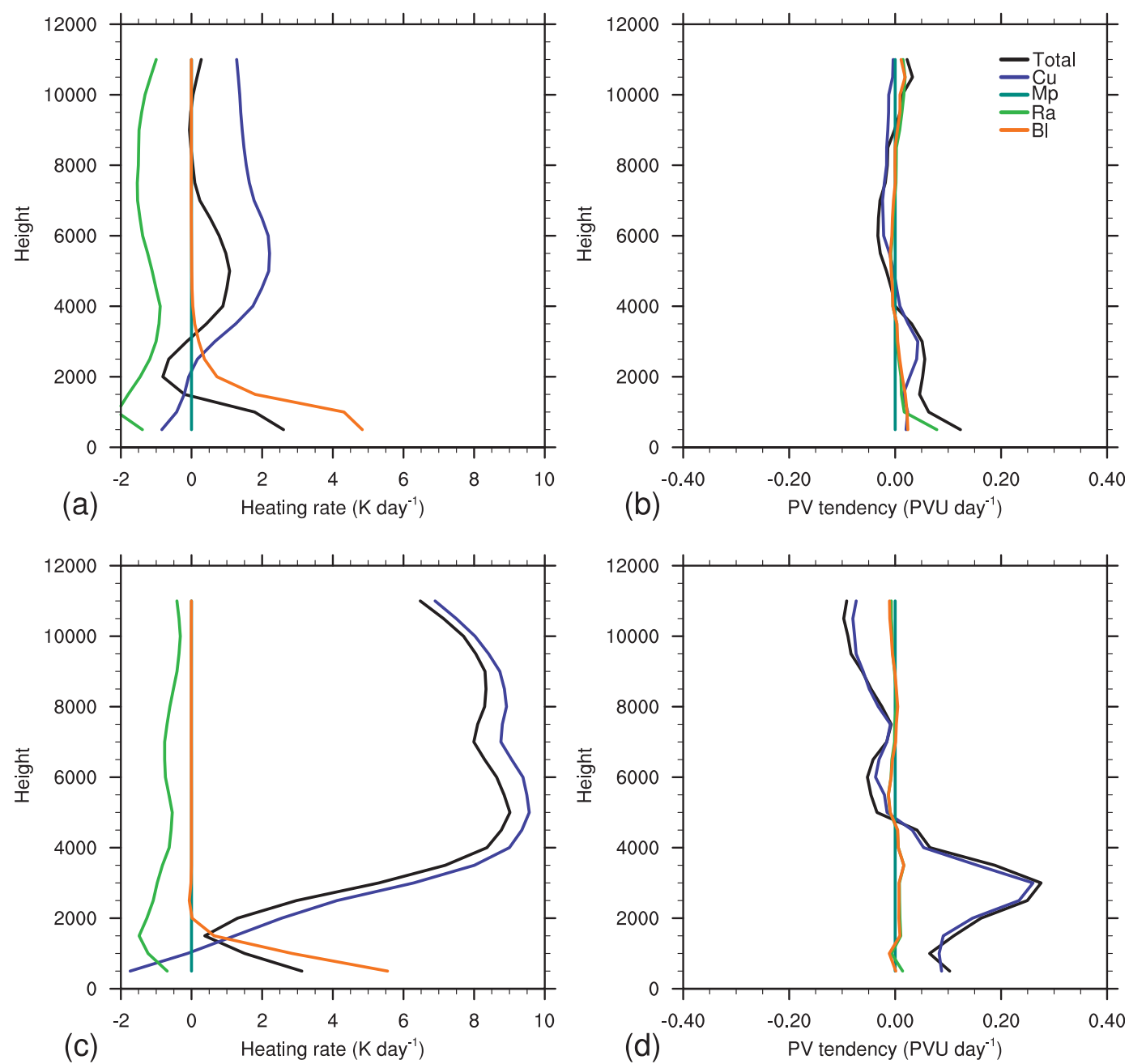

FIG. 6. Ensemble-mean, time-averaged parameterized diabatic heating terms divided into $10^{\circ}$ lon $\times 5^{\circ}$ lat boxes (top) poleward and (bottom) equatorward of the objectively defined AEW center: (a),(c) ensemble mean diabatic heating rate $\left(\mathrm{K} \mathrm{day}^{-1}\right)$ from each type of physical parameterization and (b),(d) the resultant PV tendency (PVU day ${ }^{-1}$ ). The parameterizations are displayed, according to the colors shown in (b), for $\mathrm{Cu}$ : cumulus, $\mathrm{Mp}$ : microphysics, Bl: vertical diffusion, Ra: radiation, and the net value is shown by the black line. Data from the first $24 \mathrm{~h}$ of each simulation are discarded for spinup.

$$
\mathrm{CA}=\int_{p 1}^{p 2} \frac{\overline{\left[v^{\prime} T^{\prime}\right]}}{\bar{\sigma}} \frac{\partial[T]}{\partial y} d p-\int_{p 1}^{p 2} \frac{\overline{\left[\omega^{\prime} T^{\prime}\right]}}{\bar{\sigma}} \partial \frac{\overline{[T]^{*}}}{\partial p} d p
$$

where $[(\cdot \cdot)]$ represents a zonal average and $[(\cdot)]$ an area mean of the quantity (.) (Norquist et al. 1977). A prime indicates a deviation from a zonal average and an asterisk a deviation of a zonal average from the area mean. All variables have their usual meteorological meaning and $\sigma$ represents the static stability in pressure coordinates, where

$$
\sigma=\frac{1}{g}\left(\frac{T}{c_{p}}-\frac{p}{R} \frac{\partial T}{\partial p}\right) .
$$

The quantity $Q$ represents the diabatic heating rate and is converted to pressure coordinates via

$$
Q=\dot{\theta} c_{p}\left(\frac{p}{p_{0}}\right)^{R / c_{p}},
$$

where $\dot{\theta}$ is the total diabatic heating tendency, which is output directly from the WRF simulations. The GE term represents the generation of eddy available potential energy by diabatic heating and the CA term represents conversion of basic-state potential energy to eddy available potential energy. The justification for considering only the terms associated with the generation of the eddy available potential energy is that this is the only term in the Lorenz energy cycle where both diabatic and adiabatic processes can contribute (see Norquist et al. 1977).

The time series for both of these quantities, vertically integrated and computed using a $10^{\circ} \times 10^{\circ}$ box following 

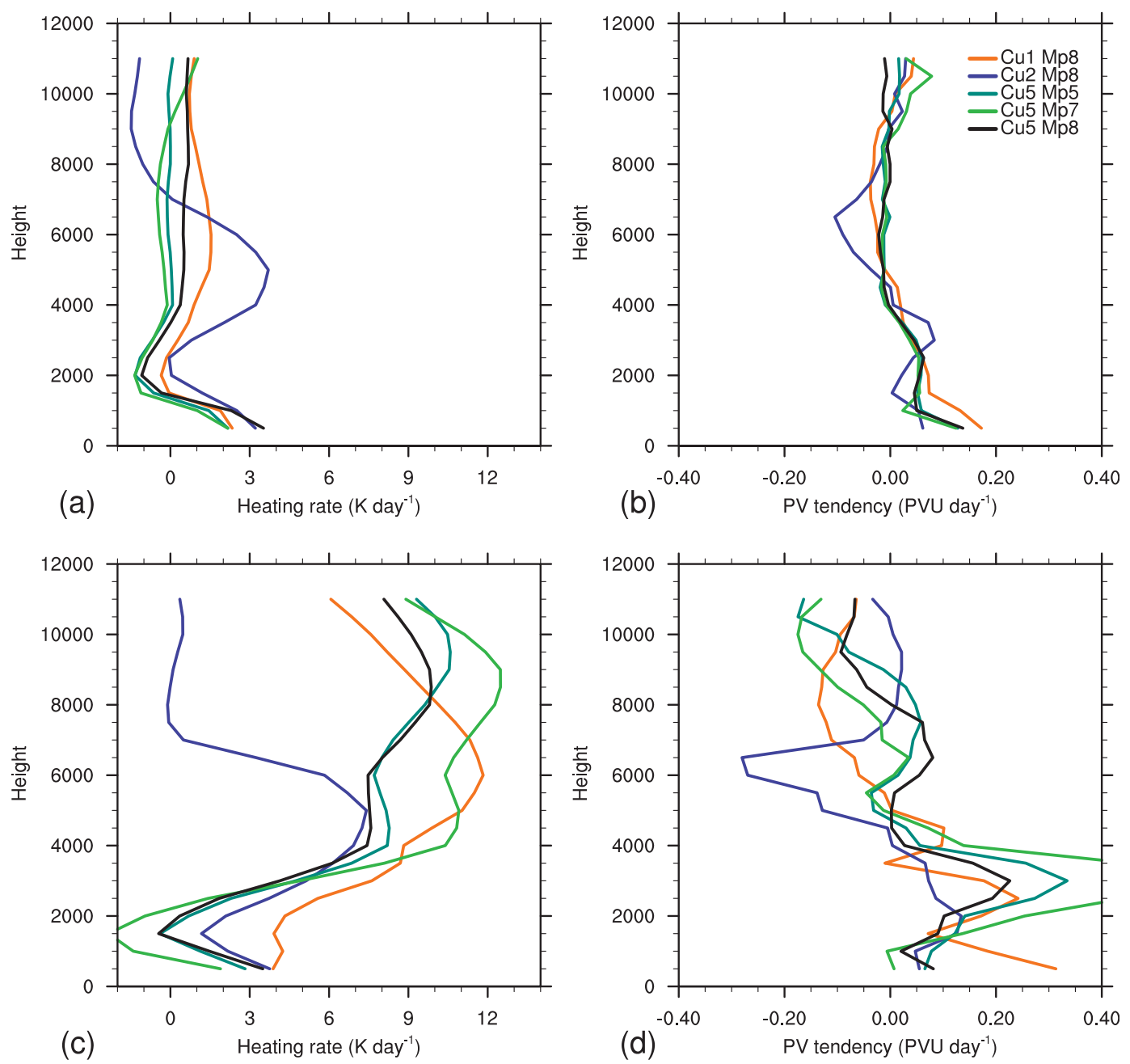

FIG. 7. As in Fig. 6, but for the net diabatic heating rates and PV tendencies in each member of the WRF ensemble. The different ensemble members are signified by the colors (see Table 1 for member details).

the objective AEW center, is shown in Fig. 8 for each of the WRF simulations and the ensemble mean. The CA time series (Fig. 8a) are positive throughout the course of all simulations and the ensemble mean value increases in a similar fashion to the mean PV time series (Fig. 5). As this term has a dependence on both meridional wind and temperature anomalies, the growth of this term in concert with the overall increase in AEW intensity, shown on the Hovmöller diagrams in Fig. 2, is to be expected. There is a clear diurnal cycle superimposed on the positive CA trend with peaks occurring near 1600 UTC. The GE terms (Fig. 8b) are predominantly positive during the integration. Unlike the ensemble mean CA, the ensemble mean GE term increases until $90 \mathrm{~h}$ into the simulation, after which there is an overall decrease. Further analysis indicates that this marked change in the GE time series coincides with the termination of one region of organized convection and the formation of a new area of convection in most of the simulations. Diurnal variation of the GE term is also noted, with peaks occurring near 2000 UTC, which is approximately the time when the maximum number of squall lines is observed (Fink and Reiner 2003). Both energetic terms from the simulation using the BMJ cumulus parameterization stand out as different from the other simulations. Although the general behavior is the same as the other members, the energetic terms are significantly larger; given that the convective parameterization should only affect the GE term in a direct way [via the $Q$ term in Eq. (1)], this suggests that convection does have an impact on the "dry" dynamics of the AEW.

In all simulations the ratio of the two energetic terms is $O(1)$ in all five WRF simulations, including the BMJ case. This implies that both adiabatic and diabatic processes are equally important in the overall evolution of the AEW. Sensitivity tests, conducted by halving and doubling the 

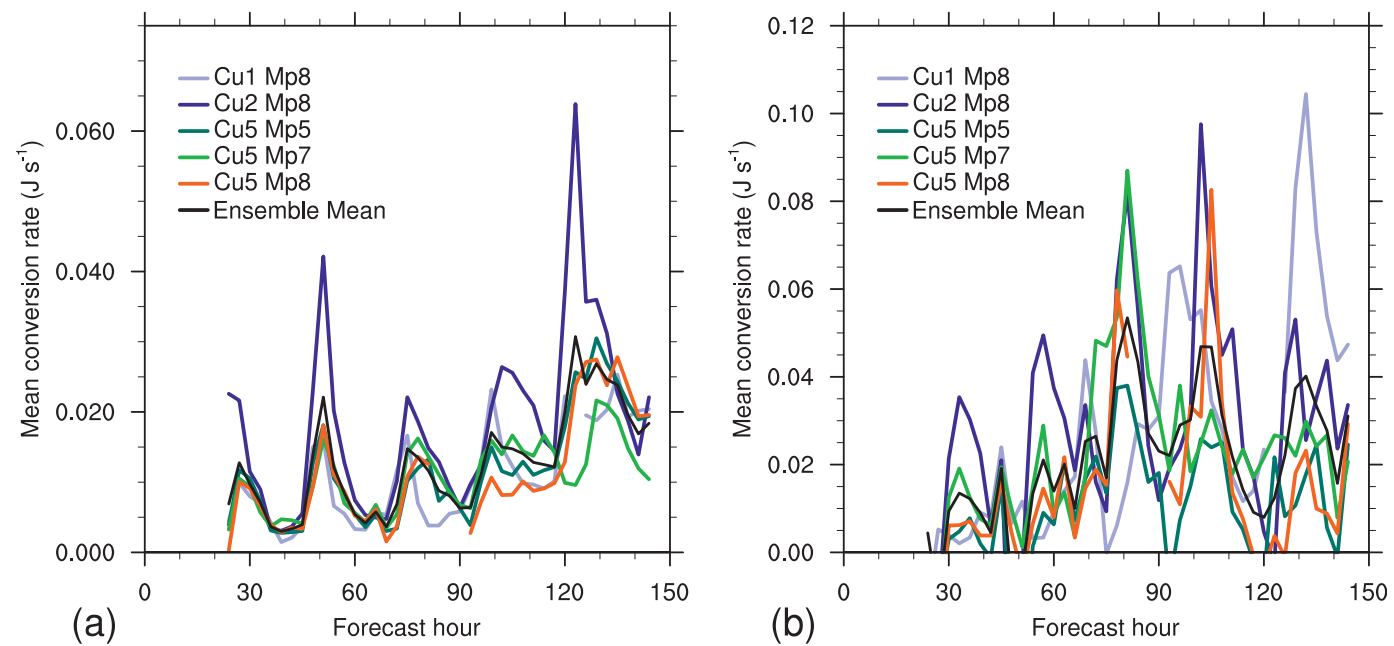

FIG. 8. Time series of Lorenz (1955) energetic terms averaged between 900 and $100 \mathrm{hPa}$ in a system following $10^{\circ} \times$ $10^{\circ}$ box centered on the objectively defined AEW center at $700 \mathrm{hPa}$ : (a) the CA term [Eq. (2)] and (b) the GE term [Eq. (1)]. Each WRF simulation is indicated with a different color and the ensemble mean is shown in black.

size of the box used for computation, result in the mean ratio between the two quantities remaining of order 1 , thereby indicating the robustness of the result.

Further interpretation of the energetics with respect to the synoptic structure is given by examining the time mean spatial distribution of the GE and CA terms from the WRF ensemble, displayed in Fig. 9. The cross section of the baroclinic term (CA, Fig. 9a), zonally averaged across the system following domain displayed in Fig. 4, has its largest amplitudes at low levels near the AEW center, where the meridional temperature gradients are maximized. The largest positive values occur near $900 \mathrm{hPa}$ and slope equatorward with height, approximately following sloped potential temperature contours that separate the monsoon and Saharan air masses. This figure closely resembles Fig. 4 of Norquist et al. (1977), which displays the first term in Eq. (2) derived from field data from the Global Atmospheric Research Program Atlantic Tropical Experiment. The figure mirrors the regional modeling results of Hsieh and Cook (2008, their Fig. 11), who examined the energetics of AEWs from a climatological perspective using a fixed, rather than system relative, area average. A horizontal map at $900 \mathrm{hPa}$ (the level of maximum values) is shown in Fig. 9c for comparison with the mean synoptic features in Fig. 4. The CA term is maximized within synoptic-scale maxima along the baroclinic zone where the largest meridional excursions of potential temperatures occur in the mean (Fig. 4a).

The average GE term shown by cross section in Fig. $9 \mathrm{~b}$ and horizontal map at $400 \mathrm{hPa}$ in Fig. 9d indicates that this term is relatively confined to the region $0-400 \mathrm{~km}$ south of the AEW center, closely corresponding to the footprint of precipitation (see Fig. 4b). In the vertical, the GE term extrema coincide with maximum vertical motion in the mean and is negative below $700 \mathrm{hPa}$ (approximately the level of the peak AEJ) and positive above, consistent with Hsieh and Cook (2007, their Fig. 12). Because the diabatic heating profiles (Fig. 6) are positive above $1 \mathrm{~km}$ [i.e., $Q^{\prime}>0$ in Eq. (1)], this is anticipated as, via PV thinking, there would be a cold anomaly [i.e., $T^{\prime}<0$ in Eq. (1)] below the midlevel PV maximum and a warm anomaly above.

\section{d. Dry run simulation}

Although the Lorenz energy cycle is useful in determining if either adiabatic or diabatic energy conversions are dominant, they provide an instantaneous metric of the role of convective heating but do not fully describe how convection dynamically influences the overall evolution of the AEW. To precisely evaluate how convection influences the evolution of the flow field, elaborating on the conceptual model of BT05, an alternative perspective needs to be taken. One method, often employed in midlatitude dynamics (e.g., McTaggart-Cowan et al. 2001) is that of "PV inversion" (see Hoskins et al. 1985) whereby the individual flow and temperature characteristics of a particular feature can be assessed. While this is an appealing and succinct method with which to diagnose the flow and address the questions, a suitable balance criterion (e.g., geostrophic) for the PV anomalies is required (Davis and Weisman 1994). In this case the impact of numerous: subsynoptic-scale features at low latitude needs to be considered, which means that the choice of a suitable balance criterion and the computation required is nontrivial and accordingly the results are subject to very large uncertainties. 

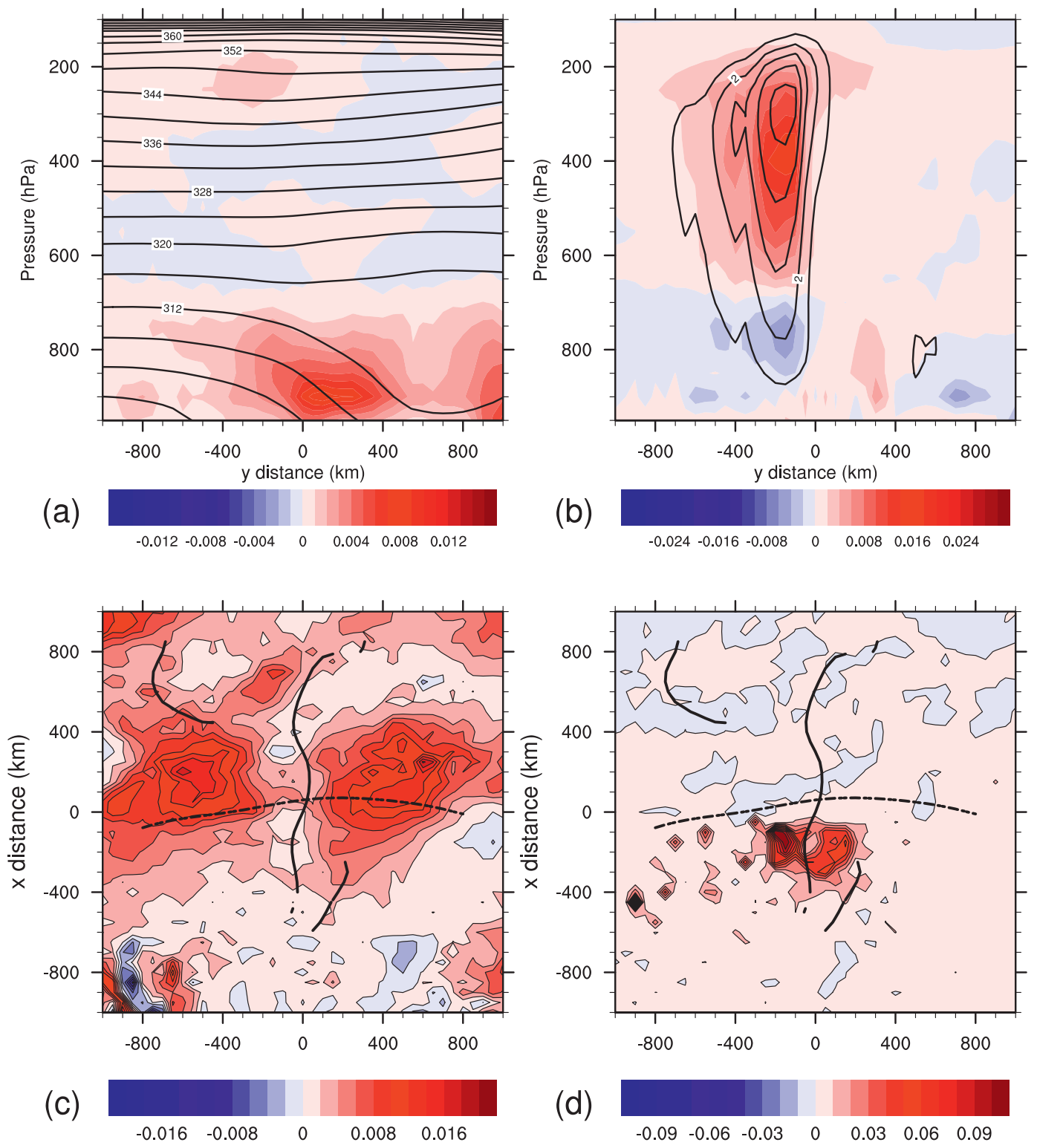

FIG. 9. WRF ensemble-mean, time-averaged energetic terms in a frame of reference based on the objectively defined AEW center at $700 \mathrm{hPa}$ : (a) vertical cross sections of the CA term ( $\mathrm{J} \mathrm{s}^{-1}$, shaded) and potential temperature (K, contoured), both zonally averaged across the system relative domain shown in Fig. 4, and (b) vertical cross sections of the GE term $\left(\mathrm{J} \mathrm{s}^{-1}\right.$, shaded) and vertical motion $\left(\mathrm{cm} \mathrm{s}^{-1}\right.$, positive values $>1 \mathrm{~cm} \mathrm{~s}^{-1}$ contoured every $1 \mathrm{~cm} \mathrm{~s}^{-1}$ ) both zonally averaged across the system relative domain shown in Fig. 4. Horizontal maps of (c) the CA term at $900 \mathrm{hPa}$ and (d) the GE term at $400 \mathrm{hPa}$, both overlain with the objective 700-hPa trough (thick black lines) and jet (dashed black lines) axes. Data from the first $24 \mathrm{~h}$ of the simulations are not used.

To diagnose the role of convection in this AEW case, the main WRF simulation is rerun from its midpoint with convective processes removed and the role of convection in the evolution of the AEW assessed based on the differences between this dry run and the main simulation. Since the physical processes associated with convection have been entirely parameterized in the WRF simulations, the dry run comprises the same model configuration but with no cumulus or microphysical parameterizations. Although this is actually tantamount to the removal of all precipitation processes (including large-scale nonconvective precipitation), this procedure is justified by the fact that the precipitation over tropical North Africa during summer predominantly occurs in association with deep convection as opposed to large-scale ascent (cf. Laing et al. 1999). The parameterization schemes for 
vertical mixing and radiation remain in the simulation in order to maintain the large-scale monsoon (which is driven in part by sensible heating over the Sahara) and as realistic a basic state as possible. Through direct experimentation it was noted that prolonged integration (5 days or more) without the cumulus or microphysical parameterization results in an gradual equatorward shift in the location of the AEJ [consistent with the results of Thorncroft and Blackburn (1999)], so the dry run is kept as short as practical. The dry run begins from the main simulation at $72 \mathrm{~h}$ (1200 UTC 6 September) into the original simulation when the $\mathrm{AEW}$ is near $10^{\circ} \mathrm{E}$ and at the start of a period of growth (see Figs. 2 and 5).

Hovmöller diagrams of the $700-\mathrm{hPa}$ meridional wind are shown for both the main simulation and the dry run in Fig. 10. It is clear that the dry synoptic AEW continues to propagate westward with approximately the same phase speed in the absence of convection. At the end of the simulation, the peak $700-\mathrm{hPa}$ meridional wind associated with the AEW in the dry run is approximately half of the value in the original simulation. Consistent with the Hovmöller diagram, the synoptic fields (not shown) are similar to the original simulation, albeit with less intensity, and the synoptic characteristics are still readily identifiable as an AEW. This suggests that, although convection may be vital for the growth of AEWs, the synoptic system can continue to exist even if convection is suppressed for several days. This supports the conclusion of Hsieh and Cook (2008), who found that instabilities of the AEJ sustain AEWs in their decaying stages rather than in their initiation. An interesting aside is that in the dry run the second AEW (present near $30^{\circ} \mathrm{E}$ at the start of the dry run), which was overintensified in all members of the WRF ensemble, is still evident but does not amplify so markedly in the dry run. This lack of growth in the absence of convection is consistent with Hall et al. (2006) as well as Hsieh and Cook (2007).

Following the convention of Fig. 5, Fig. 11 shows a time series of $1-5-\mathrm{km}$ averaged PV averaged in a $10^{\circ} \times$ $10^{\circ}$ system-relative box following the AEW in both the original and dry run simulations. It is evident that at the start of the dry run the mean PV values significantly decrease. The diurnal cycle is still present as the diabatic terms associated with radiation and vertical mixing are still active in the model. By the end of the simulation the mean PV value in this layer is less than half of that in the original simulation and smaller than the original value. The time series of the energetic terms from the dry run are shown in Fig. 12. Both terms decrease to close to zero for most of the dry run period. This is important as if convection was dynamically passive the time series of the CA term would be practically the same as in the original simulation. This implies that, aside from its direct effect via latent heat release, convection also has a vital upscale impact on the synoptic AEW structure and its growth, consistent with the conceptual model present by BT05.

\section{Comparison with the ERAI composite}

For the results and conclusions in this research to be more generally applicable, it must be demonstrated that the case examined is generally representative of other AEWs. Figure 13 shows the composite structure of 430 AEW cases detected using the objective diagnostics in the region $10^{\circ} \mathrm{W}-10^{\circ} \mathrm{E}$ in the ERAI. When compared with Fig. 4, it is clear that the overall synoptic structure of the composite is extremely similar to that generated from the WRF simulations. In particular, the ERAI composite exhibits a wavelike structure in the low-level potential temperature field, with the warm part of the wave located poleward and west of a PV maximum in the midtroposphere. The TRMM rainfall is maximized equatorward of the AEJ axis, with peak values ahead (west) of the midlevel trough axis. The main differences between the ERAI composite and the WRF ensemble mean are that the simulated case has a longer wavelength (by approximately $500 \mathrm{~km}$, evident from the $925-\mathrm{hPa}$ streamlines) and the simulated rainfall covers a smaller region, but is more intense. These differences are likely a consequence of the relative sample size: thus, it is surmised that from a synoptic perspective the WRF simulations are representative of most AEW cases.

The energetics of the ERAI composite are computed using the reanalysis fields and the TRMM 3B42 rainfall estimate to estimate the diabatic heating rate in Eq. (1). As noted in the methodology, this is simulated by combining the rainfall estimate with a rainfall normalized heating profile containing both stratiform and convective elements from Schumacher et al. (2004) and is subject to large uncertainties. Maps of the mean CA and GE terms at their level of maximum intensity are displayed in Figs. 14a,b alongside the idealized diabatic heating profile used in estimating the GE term in Fig. 14c, for reference. Again, when compared to the equivalent figure from the WRF simulations (Figs. 9c,d), the ERAI composite results are very similar. In both, the CA term is peaked along the low-level baroclinic zone poleward of the AEJ axis (where the difference in system wavelength can be clearly seen) and the GE term is collocated with the maximum rainfall. Consistent with the WRF results discussed previously, the ratio between the pressure integrated GE and CA terms is $O(1)$ : thus, both adiabatic and diabatic processes appear to be equally important in the composite AEW. 


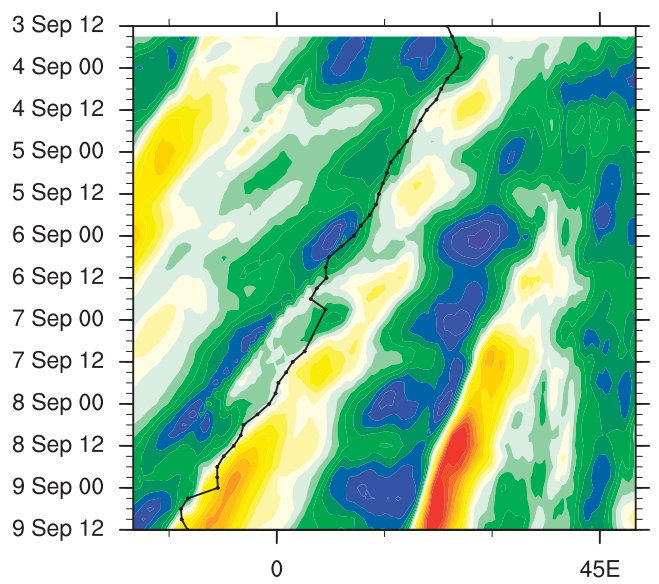

(a)

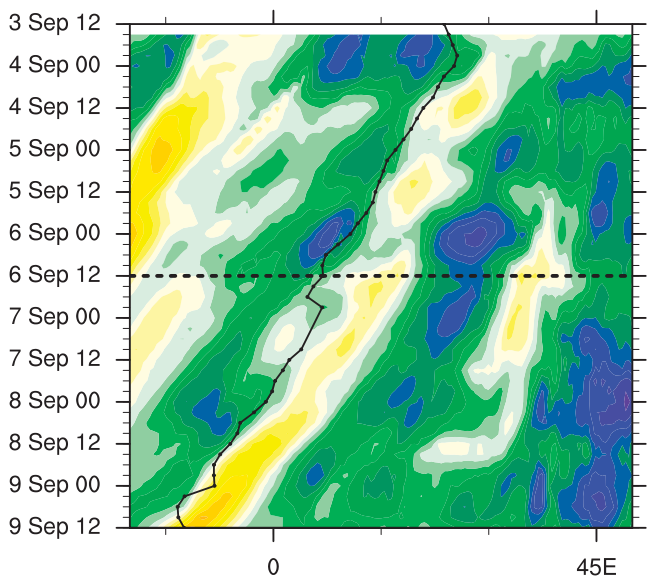

(b)

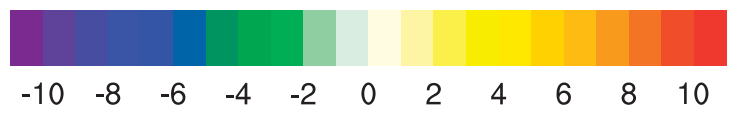

FIG. 10. Hovmöller space-time diagrams of $700-\mathrm{hPa}$ meridional wind averaged over $5^{\circ}-15^{\circ} \mathrm{N}$ for the (a) main WRF simulation (Cu5 Mp8) and (b) the dry run. The location of the objectively defined AEW center (see text for definition) is indicated by the black dots and joined with a solid line. A dashed line in (b) indicates the time at which the parameterizations were removed from the simulation.

\section{Discussion and conclusions}

Much of the focus here has been on the PV structure of the AEW and its temporal evolution in the WRF simulations. It was found that the lower tropospheric PV tended to increase almost linearly during model integration as the AEW moved across the continent. Given that the PV field weakens rapidly in the dry run, it is suggested that this increase is due, not solely to the advection of PV by adiabatic processes, but also to the diabatic heating associated with moist convection. Analysis of the diabatic PV tendency has revealed that maximum diabatic PV tendency occurs near the level of the AEJ, where there is a strong vertical gradient of diabatic heating associated with the cumulus parameterization in the WRF model. Observations of similar heating profiles are found in regions where convective systems have large stratiform rainfall regions, characterized by significant cooling at low levels due to subcloud evaporation and strong heating at upper levels due to phase changes in the mesoscale updraft (see, e.g., Houze 2004). In West Africa, mesoscale squall lines are common (see Fink and Reiner 2003), with highest rainfall rates on the leading (western) flank of the convective systems followed by substantial areas of relatively light stratiform rainfall. The distinction between convective and stratiform regions within a MCS (and their different diabatic heating profiles) may be the reason why in both the WRF ensemble mean (Fig. 4) and ERA-Interim composite (Fig. 13) the highest midlevel
PV values are located behind (east of) the peak rainfall rates.

One of the most significant conclusions from the research presented is that terms in the Lorenz energy cycle indicate that over the life cycle of the AEW the dynamical role of convection is equally important as the adiabatic dynamics for growth. These results support the

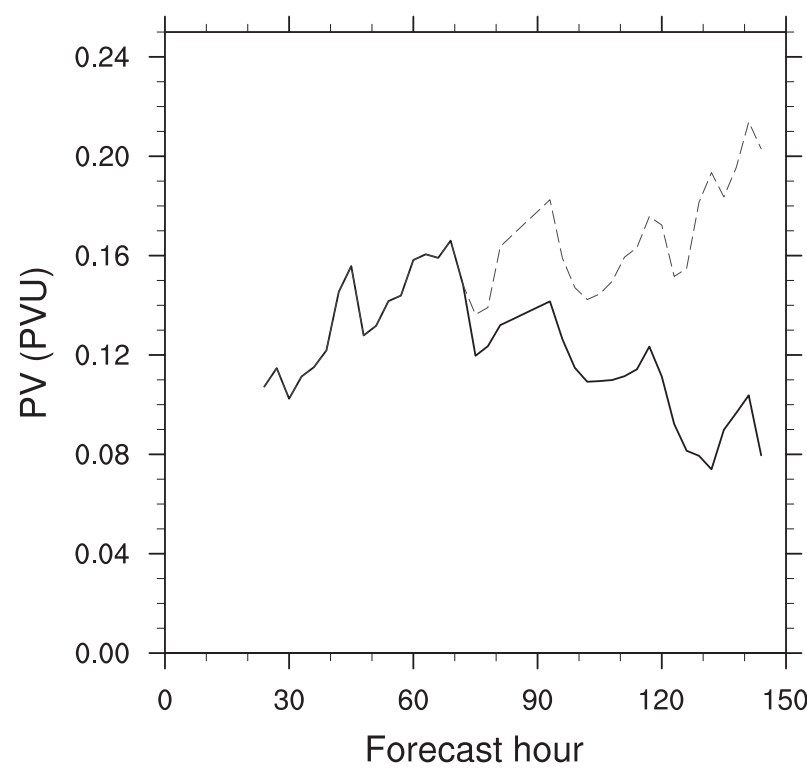

FIG. 11. As in Fig. 5, but showing only the original WRF simulation (dashed line) and the dry run experiment (solid). 


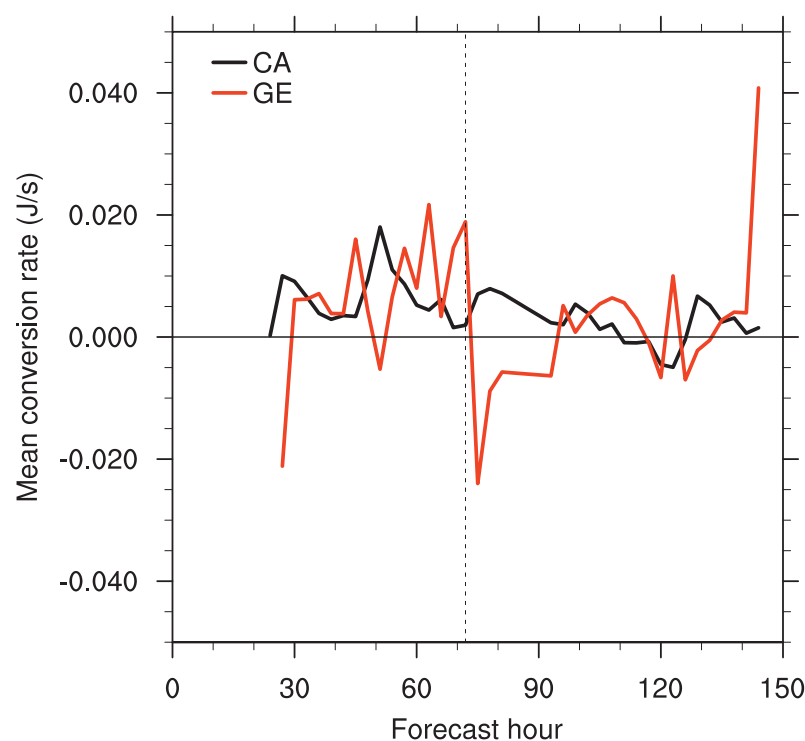

FIG. 12. Time series of Lorenz (1955) energetic terms in the dry run experiment. The vertical dashed line indicates the point at which parameterizations are removed from the simulation.

climatological study of Hsieh and Cook (2007) and clarify how the energetics relate to the synoptic structures. Based purely on the Lorenz cycle energetics, one might expect that AEWs could exist in the absence of either diabatic or adiabatic processes, as both GE and
CA terms [Eqs. (1) and (2)] were positive over the AEW life cycle. However, the "dry run" perturbation experiment, in which the convection was essentially removed, suggests that for intensification the synoptic-scale AEW requires the presence of convection. Based on this and results from previous research, it is suggested that the aggregate flow anomalies associated with convection acts as a "catalyst" for the adiabatic dynamics, consistent with the diabatic Rossby vortex concept (Parker and Thorpe 1995) and the conceptual AEW model of BT05.

The large differences in the dry energetic term [CA in Eq. (2)] between the main simulation and the dry run is consistent with the results of earlier idealized dry studies (e.g., Thorncroft and Hoskins 1994) from which it can be inferred that the growth rate of the most unstable mode of the AEJ is insufficient to produce the observed AEW amplitudes in the time it takes an AEW to cross the African continent. The layer average PV in the dry run (Fig. 11) indicates that the AEW continually weakens after the cumulus and microphysical parameterizations are switched off, rather than indicating any growth. The system likely remains coherent as the dry dynamics are still active (Hsieh and Cook 2008), but there is overall weakening as they are insufficient to prevent spindown of this AEW due to advection, mixing, and friction. Overall, this fits well with the conjecture of Norquist
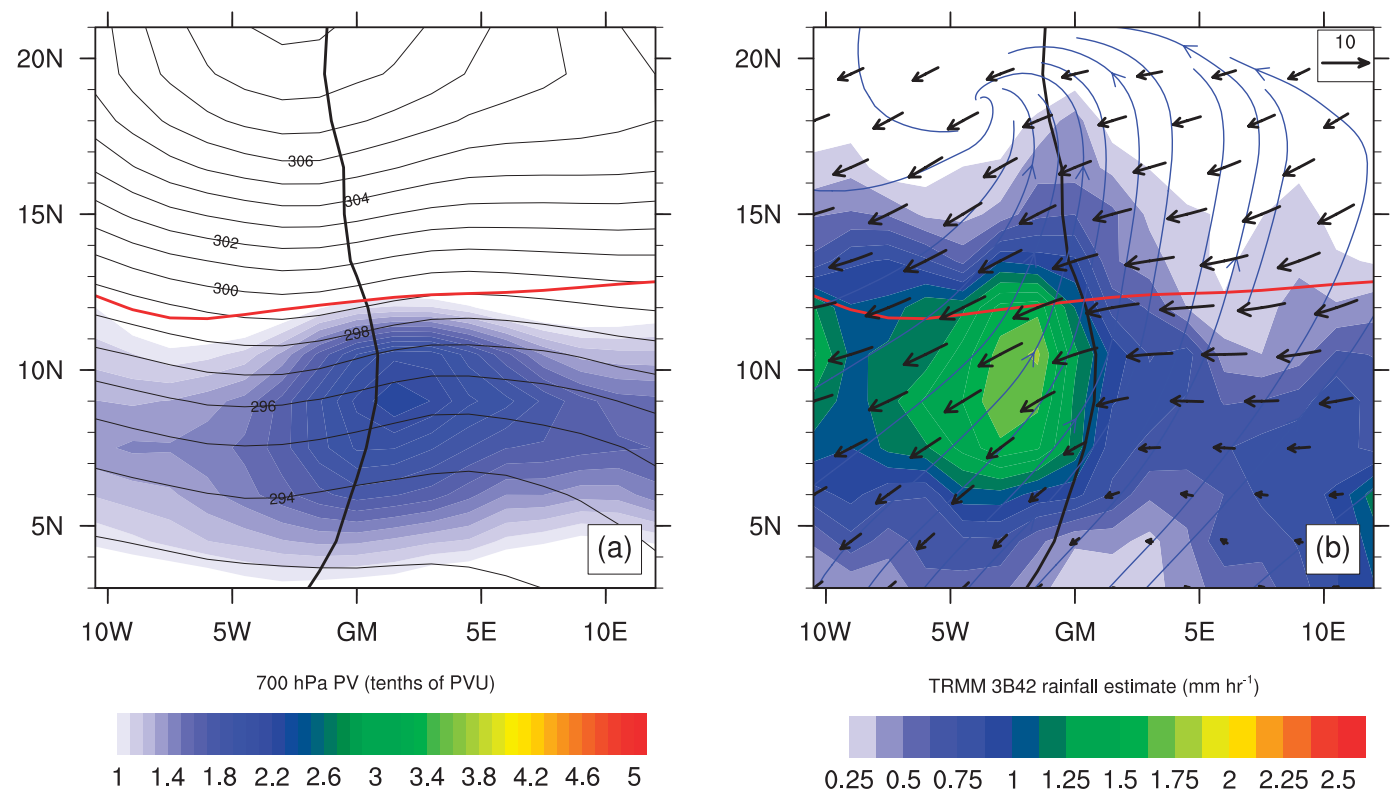

FIG. 13. Mean synoptic maps of composite AEW generated from the ERA-Interim based on objective tracking of trough axes at $700 \mathrm{hPa}$ between $10^{\circ} \mathrm{E}$ and $10^{\circ} \mathrm{W}$. Following the convection of Fig. 4, data are translated to a common longitude: (a) 700-hPa PV (shaded) and 925-hPa potential temperature (black contours every $2 \mathrm{~K}$ ); (b) mean precipitation rate from TRMM 3B42 rainfall estimate (shaded, $\mathrm{mm} \mathrm{h}^{-1}$ ), streamlines at $925 \mathrm{hPa}$, and wind vectors at $700 \mathrm{hPa}$. The objective AEW and AEJ axes at $700 \mathrm{hPa}$ are denoted by thick black and red lines, respectively, on each panel. Data consists of 430 individual cases in July-September 1989-2009. 

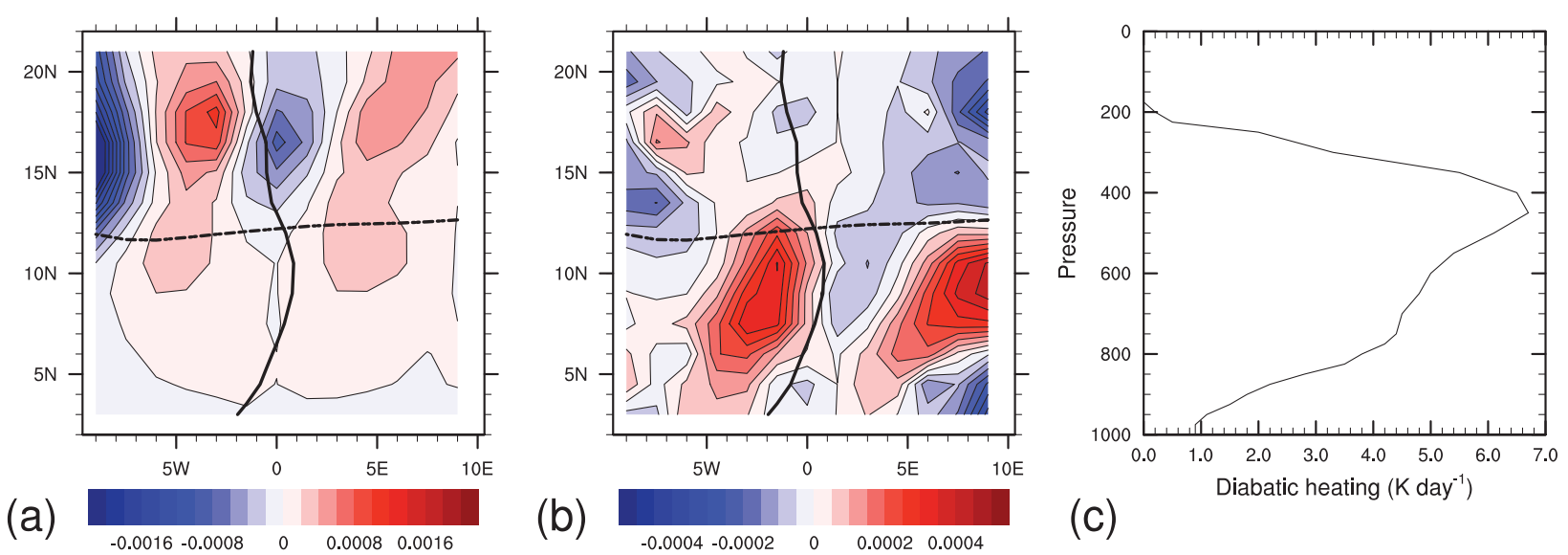

FIG. 14. Energetic terms computed using the ERA-Interim composite AEW: map of (a) the CA term (shaded, $\mathrm{J} \mathrm{s}^{-1}$ ) at $900 \mathrm{hPa}$ and (b) the GE term (shaded, $\mathrm{J} \mathrm{s}^{-1}$ ) computed using the TRMM 3B42 estimated rainfall and the idealized heating profile. The mean objective trough and jet axes at $700 \mathrm{hPa}$ are drawn in (a) and (b) using solid and dashed black lines, respectively. (c) Idealized heating profile $\left(\mathrm{K} \mathrm{day}^{-1}\right)$ for a rainfall rate of $1 \mathrm{~mm} \mathrm{day}{ }^{-1}$, adapted from Schumacher et al. (2004).

et al. (1977) and the seasonal calculations of Hsieh and Cook (2007), who point to convection as an important energy source for the growth and maintenance of AEWs.

The nature of the dry run experiment leads to further questions about how long an AEW can "survive" in a region devoid of deep convection. The dry run provides not only quantification of the role of convection for this particular case but also an analog for a synoptic situation in which an existing AEW encounters large-scale conditions that suppress convection, such as an unfavorable phase of the Madden-Julian oscillation (see Ventrice et al.2011) Although there is a significant reduction in the mean PV associated with the AEW (Fig. 11), the AEW remains a well-defined feature on the Hovmöller diagram (Fig. 10) and synoptic maps (not shown). It appears that the synoptic AEW is capable of surviving at least several days in the West African monsoon environment in the absence of convection. This has large implications for forecasting, as it suggests that, although the strong mesoscale PV centers are absent (and thus the AEW is unlikely to instantaneously spawn a tropical cyclone over the ocean), there may still be an overriding synoptic pattern that has the potential to promote and organize new convection in a favorable environment.

Based on the results presented here, which build upon many earlier studies, it is argued that the mesoscale convection and synoptic AEW are dynamically coupled, and it is not prudent to consider either as a response to one another. By examining the diabatic PV tendencies, energetics, and dry run experiment on the synoptic scale, it has been demonstrated that the upscale growth of circulation and temperature anomalies associated with convection embedded within the AEW are a vital part of the system. It is suggested that, rather than being viewed in a similar manner to midlatitude synoptic systems, in terms of adiabatic Rossby waves (where convection is essentially an "inert" by-product) AEWs should be viewed in a manner akin to the diabatic Rossby vortices described by Parker and Thorpe (1995) and as put forward by BT05. With the essential role of convection in mind, future work will consider the scale interactions in the opposite sense (i.e., how the synoptic AEW influences the intensity and distribution of convection) in order to complete this conceptual synoptic framework.

Acknowledgments. The ERA-Interim data were provided by the ECMWF. This research was supported by National Science Foundation Grants ATM0507976 and ATM0732255.

\section{REFERENCES}

Berry, G. J., and C. Thorncroft, 2005: Case study of an intense African easterly wave. Mon. Wea. Rev., 133, 752-766.

,$- \ldots$, and T. Hewson, 2007: African easterly waves during 2004-Analysis using objective techniques. Mon. Wea. Rev., 135, 1251-1267.

Burpee, R. W., 1972: The origin and structure of easterly waves in the lower troposphere of North Africa. J. Atmos. Sci., 29, 77-90.

_- 1974: Characteristics of North African easterly waves during the summers of 1968 and 1969. J. Atmos. Sci., 31, 1556-1570.

Carlson, T. N., 1969a: Some remarks on African disturbances and their progress over the tropical Atlantic. Mon. Wea. Rev., 97, 716-726.

— 1969b: Synoptic histories of three African disturbances that developed into Atlantic hurricanes. Mon. Wea. Rev., 97, 256276.

Cifelli, R., and S. A. Rutledge, 1998: Vertical motion, diabatic heating, and rainfall characteristics in north Australia convective systems. Quart. J. Roy. Meteor. Soc., 124, 1133-1162. 
Davis, C. A., and M. L. Weisman, 1994: Balanced dynamics of mesoscale vortices produced in simulated convective systems. J. Atmos. Sci., 51, 2005-2030.

Fink, A. H., and A. Reiner, 2003: Spatiotemporal variability of the relation between African easterly waves and West African squall lines in 1998 and 1999. J. Geophys. Res., 108, 4332, doi:10.1029/2002JD002816.

Hall, N. M. J., G. N. Kiladis, and C. D. Thorncroft, 2006: Threedimensional structure and dynamics of African easterly waves. Part II: Dynamical modes. J. Atmos. Sci., 63, 2231-2245.

Hoskins, B. J., M. E. McIntyre, and A. W. Robertson, 1985: On the use and significance of isentropic potential vorticity maps. Quart. J. Roy. Meteor. Soc., 111, 877-946.

Houze, R. A., Jr., 2004: Mesoscale convective systems. Rev. Geophys., 42, RG4003, doi:10.1029/2004RG000150.

Hsieh, J.-S., and K. H. Cook, 2005: Generation of African easterly wave disturbances: Relationship to the African easterly jet. Mon. Wea. Rev., 133, 1311-1327.

_ and _ 2007: A study of the energetics of African easterly waves using a regional climate model. J. Atmos. Sci., 64, 421440.

— and the generation of African waves: Reversals of the potential vorticity gradient. J. Atmos. Sci., 65, 2130-2151.

Huffman, G. J., and Coauthors, 2007: The TRMM multi-satellite precipitation analysis: Quasi-global, multi-year, combinedsensor precipitation estimates at fine scales. J. Hydrometeor. $8,38-55$.

Kiladis, G. N., C. D. Thorncroft, and N. M. J. Hall, 2006: Threedimensional structure and dynamics of African easterly waves. Part I: Observations. J. Atmos. Sci., 63, 2212-2230.

Laing, A. G., J. M. Fritsch, and A. J. Negri, 1999: Contribution of mesoscale convective complexes to rainfall in Sahelian Africa: Estimates from geostationary infrared and passive microwave date. J. Appl. Meteor., 38, 957-964.

Lorenz, E. N., 1955: Available potential energy and the maintenance of the general circulation. Tellus, 7, 157-167.

McTaggart-Cowan, R., J. R. Gyakum, and M. K. Yau, 2001: Sensitivity testing of extratropical transitions using potential vorticity inversions to modify initial conditions: Hurricane Earl case study. Mon. Wea. Rev., 129, 1617-1636.

Moore, R. W., and M. T. Montgomery, 2005: Analysis of an idealized, three-dimensional diabatic Rossby vortex: A coherent structure of the moist baroclinic atmosphere. J. Atmos. Sci., 62, 2703-2725.

Norquist, D. C., E. E. Recker, and R. J. Reed, 1977: The energetics of African wave disturbances as observed during phase III of GATE. Mon. Wea. Rev., 105, 334-342.

Parker, D. J., and A. J. Thorpe, 1995: Conditional convective heating in a baroclinic atmosphere: A model of convective frontogenesis. J. Atmos. Sci., 52, 1699-1711.

— , and Coauthors, 2005a: The diurnal cycle of the West African monsoon circulation. Quart. J. Roy. Meteor. Soc., 131, 2839-2860.

— C. D. Thorncroft, R. R. Burton, and A. Diongue-Niang, 2005b: Analysis of the African easterly jet, using aircraft observations from the JET2000 experiment. Quart. J. Roy. Meteor. Soc., 131, 1461-1482.

Reed, R. J., D. C. Norquist, and E. E. Recker, 1977: The structure and properties of African wave disturbances as observed during phase III of GATE. Mon. Wea. Rev., 105, 317-333.

Schumacher, C., R. A. Houze, and I. Kraucunas, 2004: The tropical dynamical response to latent heating estimates derived from the TRMM Precipitation Radar. J. Atmos. Sci., 61, 13411358.

Skamarock, W. C., J. B. Klemp, J. Dudhia, D. O. Gill, D. M. Barker, W. Wang, and J. G. Powers, 2008: A description of the Advanced Research WRF version 3. NCAR Tech. Note TN-475+STR, 113 pp. [Available online at http://www.mmm.ucar.edu/wrf/users/ docs/arw_v3.pdf.]

Thorncroft, C. D., and B. J. Hoskins, 1994: An idealized study of African easterly waves. I: A linear view. Quart. J. Roy. Meteor. Soc., 120, 953-982.

— jet. Quart. J. Roy. Meteor. Soc., 125, 763-786.

Ventrice, M. J., C. D. Thorncroft, and P. E. Roundy, 2011: The Madden-Julian oscillation's influence on African easterly waves and downstream tropical cyclogenesis. Mon. Wea. Rev., 139, 2704-2722. 